
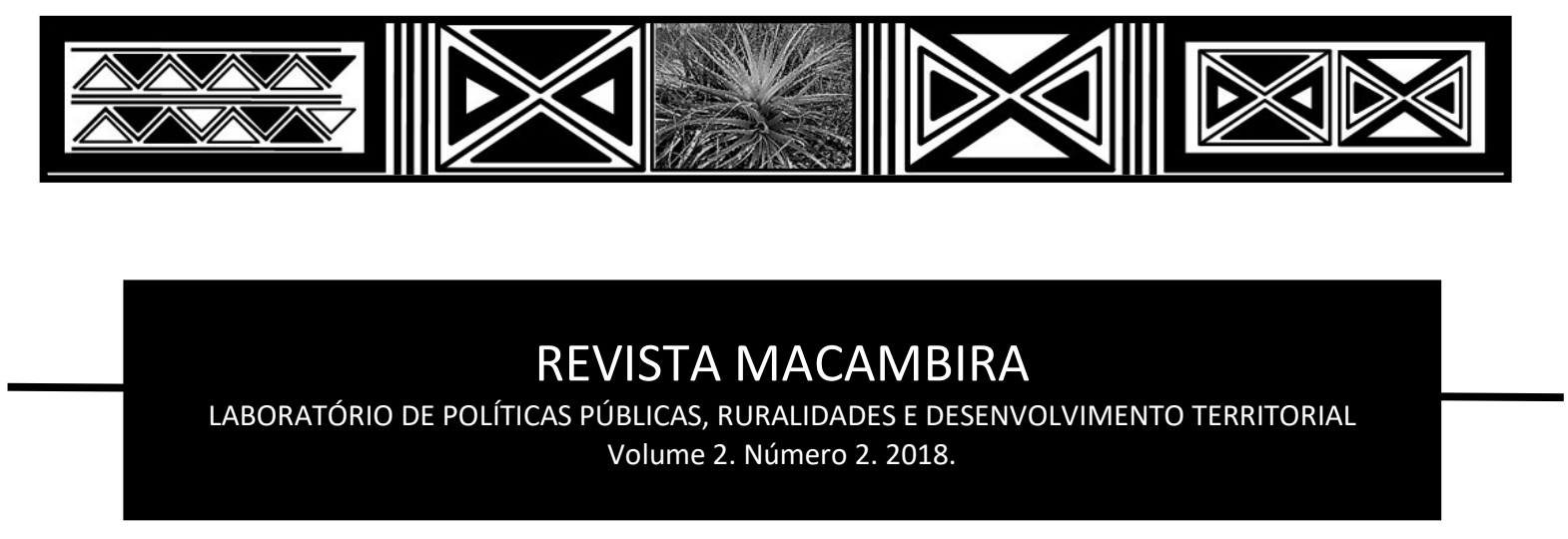

\title{
DENDÊ DE VALENÇA - BAHIA: INDICAÇÃO DE PROCEDÊNCIA
}

\author{
Lívia Liberato de Matos Reis \\ Doutoranda em Geografia UFBA; Grupo de Pesquisa Agricultura Familiar, Faculdade de \\ Economia UFBA, Praça Piedade, 6, sala 515, Salvador, Cep.: 40.070-010. Tel.: (71) 9277-2212. \\ E-mail: livialiberato@gmail.com
}

\section{Edna Maria da Silva}

Mestra em Economia UFBA; Grupo de Pesquisa Agricultura Familiar, Faculdade de Economia UFBA, Praça Piedade, 6, sala 515, Salvador, Cep.: 40.070-010. Tel.: (71) 9925-4165.

E-mail: ednasilv@yahoo.com.br

\section{Luana Santa Inês Cunha}

Graduada em Economia UFBA; Grupo de Pesquisa Agricultura Familiar, Faculdade de Economia UFBA, Praça Piedade, 6, sala 515, Salvador Cep.: 40.070-010. Tel.: (71) 9264-0143.

E-mail: victortinoco85@gmail.com

\begin{abstract}
ARTIGO

\begin{tabular}{ll}
\hline \multicolumn{2}{c}{ ARTIGO } \\
\hline Recebido: 19 de novembro de $2018 \quad$ Aceito: 20 de dezembro de 2018 \\
\hline
\end{tabular}

RESUMO: Indicação de Procedência (IP) é um tipo de propriedade intelectual. O reconhecimento de um produto registrado impede ou dificulta a aplicação de restrições sociais, etnoculturais, ambientais e outras barreiras não tarifárias. Neste artigo, considera-se um tipo especial, para fins gastronômicos, conhecido no mercado como azeite de dendê de Valença. $O$ seu processo produtivo situa-se entre artesanal e manufatureiro. Pouco mecanizado, ocupa muitas pessoas. Neste artigo procura-se demonstrar a viabilidade de um pedido de IP para o azeite de dendê de Valença. Conclui-se que o território preenche os quatro pré-requisitos regulamentares: existência de mercado consumidor para o produto; elementos específicos de produção e reconhecimento local da qualidade; organização dos agricultores familiares (cooperativa ou associação); e uma rede de suporte estatal e privado, de apoio à iniciativa.
\end{abstract}

Palavras-chave: Indicação de Procedência. Azeite de dendê. Agricultores familiares.

ABSTRACT: Indication of Origin (IP) is na intellectual property type. The recognition of registered products prevents or hinders the application of social constraints, ethno cultural, environmental and other non-tariff barriers. This article seek sto demonstrate the feasibility of an application IP to palmoil of Valença. We conclude that the region meets the four prerequisites: the existence 
of the consumer market for the product; specific elements of production and local recognition of the quality, organization of familiar producers (cooperative or association), and a network of state and private supporting the initiative.

Keywords: Indicationof Origin. Palmoil. Smallscale agriculture.

\section{INTRODUÇÃO}

O objetivo deste artigo é verificar a viabilidade de se fazer um pedido de registro de Indicação de Procedência (IP) para o azeite de dendê de Valença e municípios vizinhos. Juntos, eles integram o território Costa do Dendê, no Baixo Sul da Bahia. O produto é popularmente conhecido como "azeite de dendê da região de Valença”. O pedido, que pode vir a ser feito ao Instituto Nacional de Propriedade Industrial (INPI), deve cumprir quatro pré-requisitos regulamentares: 1) existência de mercado consumidor para o produto; 2) elementos específicos de produção e reconhecimento local da qualidade; 3) organização dos produtores - agricultores familiares - em cooperativa ou associação; e 4) uma rede de suporte estatal e privado, de apoio à iniciativa. Todos esses pré-requisitos são analisados ao longo do artigo.

Da palmeira, ou dendezeiro (Elaeisguineensis), colhem-se frutos que dão em cachos. Do seu aproveitamento obtêm-se muitos sub-produtos. Todavia, neste artigo, trata-se apenas de um sub-produto especial, vendido no mercado como azeite de dendê de Valença, bastante procurado para fins gastronômicos, como se fosse uma marca. Na região de Valença (ou território Costa do Dendê), o processo produtivo situa-se entre artesanal e manufatureiro. Por ser pouco mecanizado, ocupa muitas pessoas. O corte (coleta dos cachos) é manual. Realiza-se quase exclusivamente por homens, tanto em palmeiras espontâneas quanto em cultivos racionais. No primeiro caso, pode-se considerar extrativismo. Após o corte, os cachos são transportados por animais até as unidades de beneficiamento (rodões). Os frutos são retirados e cozidos durante todo o dia. A polpa obtida é levada para um equipamento de extração do azeite. O processo, que dura oito dias, é concluído com lavagem, filtragem e acondicionamento. O produto final é vendido na região e em Salvador, onde é considerado ingrediente fundamental da culinária afro-baiana, sobretudo nos pratos conhecidos como moqueca, vatapá, caruru, acarajé e abará. Além da gastronomia, o palmoil não se restringe apenas ao mercado regional ou nacional. Considerados os diversos usos, o seu consumo tornou-se universal, desde que países da Ásia tornaram-se os maiores produtores mundiais. 
Como em quase todos os mercados, o mercado de palmoil também é objeto de restrições, particularmente quando o produto é usado como alimento. Maia (2004, p.155) lembra que o Instituto de Pesquisa Econômica Aplicada (IPEA), ao pesquisar 400 empresas, chegou ao seguinte resultado: "não só na Europa e América do Norte, mas também no Mercosul, as barreiras não tarifárias, são os principais obstáculos enfrentados por exportadores brasileiros". Todavia, com o registro de uma Indicação Geográfica (IG), boa parte dessas barreiras deixaria de existir para os municípios abrangidos pelo território Costa do Dendê. Lemos et al. (2005, p.360) advertem que "a política industrial foca a firma e/ou setor produtivo, enquanto a unidade de planejamento da política regional é o território." Sabe-se que é difícil e caro obter um reconhecimento internacional. Não menos difícil é combater barreiras criadas por razões sociais, étnico-culturais e ambientais. No mercado global, a qualidade deixou de ser exclusivamente "técnica". Assim, espera-se que este artigo venha a ser um primeiro passo para o diagnóstico que poderá compor um futuro processo de requerimento de IP para o azeite de dendê de Valença.

Além desta introdução, o artigo contém três seções e considerações finais. $\mathrm{Na}$ primeira seção, faz-se uma revisão histórica e se define Indicação Geográfica (IG), Indicação de Procedência (IP), e Denominação de Origem (DO). Na segunda, trata-se do produto azeite de dendê. A terceira contém uma análise dos quatro pré-requisitos. Nas considerações finais, os resultados da análise confirmam a existência desses pré-requisitos na região de Valença, o que torna viável a iniciativa de requerimento de um registro de IP para o território Costa do Dendê.

\section{INDICAÇÃO GEOGRÁFICA}

Indicação Geográfica (IG) consiste em uma modalidade de certificação para produtos e serviços, especificamente, trata-se de um reconhecimento, de um registro. Para melhor compreensão do conceito, importa conhecer sua origem histórica, as razões que determinaram a sua utilização e sua disseminação no mundo.

\subsection{BREVE HISTÓRICO DA INDICAÇÃO GEOGRÁFICA NO MUNDO}

A IG surge da necessidade de validar a qualidade diferenciada que os produtos apresentam a partir de características específicas de seu território, seja no modo de produzir ou até mesmo na geografia da região. Os produtores de um determinado território buscam, assim, evitar que grupos ou pessoas de outras localidades utilizem indevidamente o nome de uma região. 
Esse tema ganhou maior relevância no século XIX quando se iniciou um processo de determinação de meios de garantir uma regulamentação no âmbito internacional para a IG. A Convenção da União de Paris (CUP) em 1883, o Acordo de Madri (1891), o Acordo de Lisboa (1958) e o Acordo sobre os Aspectos dos Direitos da Propriedade Intelectual referente ao Comércio (ADPIC), de 1994, representam a evolução da proteção jurídica internacional dos direitos da propriedade intelectual, de que as IG fazem parte.

Tratando-se de propriedade intelectual, a IG também se insere no acordo sobre Aspectos dos Direitos de Propriedade Intelectual relacionados a Comércio (acordo TRIPS ou acordo ADPIC, 1994), que surge com o intuito de reduzir as distorções no comércio internacional e proteger o direito da propriedade intelectual. A partir de 1994, período de adoção do acordo, a IG se insere num espaço de proteção mais amplo já que houve uma adesão maior de países no acordo TRIPS, inclusive o Brasil. O acordo TRIPS, executado pela Organização Mundial do Comércio (OMC), diferentemente dos outros tratados, passa a englobar também os serviços em seu conceito, e não apenas produtos tradables. A ADPIC trata de Direito do Autor e Direitos Conexos; Marcas; Indicações Geográficas; Desenhos Industriais; Patentes; Topografias de Circuitos Integrados; Proteção de Informação Confidencial; e Controle de Práticas de Concorrência Desleal em Contratos de Licenças. Dentro do que interessa para este artigo, transcreve-se a seguir o conceito para o acordo TRIPS de IG:

Indicações geográficas são, para os efeitos deste Acordo, indicações que identifiquem um produto como originário do território de um Membro, região ou localidade deste território, quando determinada qualidade, reputação ou outra característica do produto seja essencialmente atribuída à sua origem geográfica. Com relação às indicações geográficas, os Membros estabelecerão os meios legais para que as partes interessadas possam impedir: (a) a utilização de qualquer meio que, na designação ou apresentação do produto, indique ou sugira que o produto em questão provém de uma área geográfica distinta do verdadeiro lugar de origem, de uma maneira que conduza o público a erro quanto à origem geográfica do produto; (b) qualquer uso que constitua um ato de concorrência desleal, no sentido do disposto no Artigo 10bis da Convenção de Paris de 1967. (ADPIC, 2013).

A Europa destaca-se tanto na representatividade como no pioneirismo da IG. Quando o produto apresenta uma IG, independentemente da sua modalidade, 43\% dos consumidores europeus estão dispostos a pagar até 10\% a mais do valor do produto, e, aproximadamente, $11 \%$ dos consumidores europeus apresentam-se dispostos a pagar mais $20 \%$ a 30\% pelo produto que tem a sua certificação garantida (CALLIARI et al, 2007). 
O país europeu de maior tradição no estabelecimento de relação da qualidade no modo de produção local e valorização do território de origem é a França. Desde o século XVIII os franceses vivem essa experiência. Desde o reconhecimento dos territórios produtores, em 1970, a Europa destaca-se pela produção de vinhos de qualidade registrada com IG. Por exemplo, os vinhos do Porto (Portugal); Bordeaux, Provence e Champagne (França - appellation d'origine controleê); Rioja, Ribera Del Douro, Ribeiro (Espanha denominación de orígen); Sarre, Mosela e Franken (Alemanha - Gebiet); da Sicília, Puglia, Toscana (Itália - denominaz̧ionecontrollata) entre outros. No México, a tequila ilustra a IG de uma bebida alcoólica obtida de uma espécie agrícola produzida numa limitada zona no México, a agave azul (tequilianavariedad Weber). Essa proteção ocorre desde 1974. (CALLIARI et al, 2007).

Com o intuito de manter no campo sua população rural menos favorecida e também incentivar o seu desenvolvimento produtivo e conquistar o novo mercado consumidor cada vez mais exigente, a Europa passou a estabelecer regras comuns de qualidade. Atualmente, são três os tipos de certificações europeias mundialmente aceitas: as denominações de origem protegida, as indicações geográficas e as especialidades tradicionais garantidas. Para dar visibilidade internacional e ao mesmo tempo proteger os produtos de uma concorrência desleal, a Indicação Geográfica Protegida (IGP) é a garantia de que, em determinada região, existe alguma singularidade no seu processo produtivo, além da reputação e garantia da relação entre um know-how especial e o território. Especialidade Tradicional Garantida (ETG) indica a origem do produto, mas não determina a origem geográfica. O que importa é o processo produtivo, de alguma forma, diferenciado, tradicional, independentemente do local geográfico. Já a Denominação de Origem Protegida (DOP) relaciona o produto ao local geográfico. A qualidade do produto está diretamente relacionada ao saber-fazer local, tradicional, como também ao tipo do solo específico, clima, vegetação e características próprias do território, podendo assim levar o próprio nome da região.

Dado o crescente aumento da consciência ambiental do mercado consumidor, tanto na Europa como no Brasil criam-se atualmente diversos tipos de selos de qualidade socioambiental. Na Europa, o selo de agricultura biológica assegura quanto ao uso de agrotóxicos e produtos geneticamente modificados; a Apelação de Origem Controlada (AOC) certifica a produção desde a matéria-prima ao produto final, abrangendo os agroalimentares; lacticínios; os vinhos e outras bebidas fermentadas. No Brasil existe o certificado orgânico que se assemelha ao Europeu, de agricultura biológica; o selo combustível social, do governo federal, que envolve a produção do biodiesel, e muitos outros 
selos que demonstram a tendência do mercado de valorização de produção local, especializada e consciente (REIS 2008).

Seguindo a tendência mundial de valorização das IG, faz-se necessário um estudo das duas modalidades brasileiras: a Indicação de Procedência (IP) e a Denominação de Origem (DO). Calliari et al (2007) apontam ainda a procura pela IG em países de diferentes continentes:

\begin{abstract}
A Europa, em sua história antiga e atual, tem utilizado as IG como uma importante ferramenta de valorização de seus produtos tradicionais. Mais recentemente, é na economia de nações emergentes, como Índia e China, por exemplo, que está o reconhecimento expressivo de novas indicações, apresentando ao mundo um conjunto de produtos tradicionais, sob a égide da garantia da procedência, à qual se associa uma "qualidade original" (CALLIARI et al, 2007, p.1).
\end{abstract}

A tendência atual é aproveitar o sucesso da experiência europeia, região de origem da IG e onde ainda se concentra o maior número de certificações e incorporação desta prática como diferencial competitivo, aproveitado, sobretudo por países emergentes.

\title{
2.2 INDICAÇÃO GEOGRÁFICA NO BRASIL
}

No Brasil, o primeiro produto e território registrado enquanto IG do tipo IP foi o vinho produzido no Vale dos Vinhedos, RS, em 2002. Uma IG apresenta-se na forma de IP e DO. A primeira busca proteger algum aspecto cultural ou tecnológico, como o processo produtivo, as ferramentas ou outras características próprias de um território. Uma IP contribui para a afirmação de um processo de desenvolvimento local, permitindo unir elementos de identidade coletiva e fatores diferenciais a produtos, agregando-lhes valor e diferenciando-os através do aproveitamento das tipicidades locais-territoriais e dos patrimônios culturais e sociais específicos, potencializando assim os agentes econômicos locais e revalorizando o território. A DO é uma certificação mais ampla, pois, além dos aspectos já citados, deve observar características próprias na geografia da região, como particularidades do terreno ou solo.

Desde a experiência do Vale dos Vinhedos, já foram registradas 31 IG, sendo 22 do tipo IP e 07 do tipo DO. São elas: Café Região do Cerrado Mineiro; Vinhos Vale dos Vinhedos (IP e DO); Carne bovina e seus derivados, Pampa Gaúcho; Aguardentes Paraty; Uvas de mesa e manga, Vale do Submédio, São Francisco; Couro acabado, Vale dos Sinos; Vinhos Pinto Bandeira; Arroz Litoral Norte Gaúcho (DO); Café Região da Serra da Mantiqueira, do estado de Minas Gerais; Camarões Costa Negra (DO); Artesanato em Capim 
Dourado - Região do Jalapão, no estado do Tocantins; Doces finos tradicionais e de confeitaria Pelotas, Panelas de barro Goiabeiras; Queijo Serro Minas Gerais; Peças artesanais em estanho, São João Del Rei; Calçados Franca, São Paulo; Vinhos de Uva Goethe, Vale de Uvas Goethe; Queijo Canastra Minas Gerais, Opalas preciosas de Pedro II, Piauí; Gnaisse, Região Pedra Carijó, Rio de Janeiro (DO); Gnaisse, Região Pedra Madeira, Rio de Janeiro (DO); Gnaisse, Região Pedra Cinza, Rio de Janeiro (DO); Mármore Cachoeira de Itapemirim; Própolis vermelha Manguezais, de Alagoas (DO); Cacau em amêndoas, Linhares; Café verde em grão Norte Pioneiro de Paraná; Têxteis em algodão colorido, Paraíba; Aguardente de cana tipo cachaça, Salinas; Serviços de Tecnologia da Informação Porto Digital; Vinhos Altos Montes.

Inicialmente restrita a produtos agrícolas e seus derivados, a IG e suas classificações tem-se expandido também para o setor de serviços.

Mesmo se a intenção for requerer o benefício da proteção da espécie denominação de origem, podemos imaginar o vínculo com os fatores naturais e humanos em serviços de hotelaria em uma região no Amazonas na qual seja construído um hotel cuja arquitetura seja essencialmente associada ao meio ambiente, que preserve suas características naturais e proporcione aos hóspedes uma visão privilegiada deste ambiente a partir de todas as habitações; tudo isso associado a um notório saber fazer da rede hoteleira. No caso de um SPA seria possível uma denominação de origem, por exemplo, supondo que os serviços prestados neste SPA oferecem tratamentos com lama ou pedras de procedência da região, que seriam os fatores geográficos associados (CALLIARI et al, 2007, p.7).

No caso dos serviços, portanto, devem-se preservar os elementos essenciais de uma IG: as características próprias de uma região e associação com características geográficas singulares. Dentre as experiências já realizadas no Brasil, Calliari et al (2007) apontam alguns elementos importantes como a existência de uma organização de produtores locais comprometida com a certificação, o apoio e auxílio técnico de órgãos estatais e da sociedade civil e a presença dos elementos próprios de uma IG, como características singulares reconhecidas.

Destacam-se alguns casos bem sucedidos, um deles é o vinho do Vale dos Vinhedos, RS. Os produtores se organizam em associações locais, incentivando a pesquisa, buscando a preservação do espaço físico, o estímulo ao turismo e a profissionalização da produção e comercialização, além da preservação das características próprias de uma IG. Com essas 
ações, obtiveram-se resultados expressivos dentre eles a valorização das propriedades rurais da área geográfica. O desenvolvimento regional é representado pela maior oferta de empregos no campo, na indústria, no turismo, na construção civil e nos serviços, a elaboração de um plano diretor para a região, com a participação de comunidades locais visando ordenar o desenvolvimento da zona rural, preservando a vocação local (CALLIARI et al, 2007).

Dentre alguns dos benefícios encontrados em experiências brasileiras, Valente et al (2012) destacam os importantes ganhos socioeconômicos. Detecta-se uma melhor distribuição do valor agregado ao longo da cadeia de produção, do produtor da matériaprima até o fabricante, promovendo-se também a valorização de territórios pouco favorecidos, com o desenvolvimento da produção local e uma melhor distribuição de renda.

\subsection{ASPECTOS CONCEITUAIS}

Para conceituar Indicação Geográfica é necessário compreender os elementos motivadores que determinaram o seu surgimento. Calliari (2007) aponta a IG como uma resposta ao problema da "assimetria de informação":

O conceito de indicações geográficas desenvolveu-se lentamente no transcurso da história, e de modo natural, quando produtores, comerciantes e consumidores comprovaram que alguns produtos, advindos de determinados lugares, apresentavam qualidades particulares, atribuíveis a sua origem geográfica, e passaram a denominá-los com o nome geográfico de procedência. Foi uma resposta ao que os economistas, séculos depois, chamariam de problema de assimetria de informação. No caso, a indicação geográfica era uma garantia, para comerciantes e consumidores, de que o produto tinha certa qualidade, o que facilitava a realização de transações sem a presença física do produto. (CALLIARI et al, 2007, p.1).

A IG objetiva garantir segurança nas transações econômicas, promovendo a mediação entre um produto com características singulares e os consumidores e fornecedores que buscam tais atributos. Assim, torna-se possível proteger o produto de barreiras não tarifárias, política indireta de proteção à entrada de produtos nacionais no mercado internacional praticada por muitos países importadores que visam bloquear a entrada do produto concorrente no mercado interno do país. Um produto certificado que engloba requisitos básicos de saneamento, segurança e qualidade de produção fica protegido desse tipo de política internacional. 
Além de reunir características de uma certificação, a IG é definida, por alguns autores, como exemplificam Valente et al (2012), como um direito de propriedade intelectual autônomo de caráter coletivo, distinguindo-se, assim, das patentes e marcas. Isso quer dizer que ela não é uma garantia a um agente privado específico, mas a qualquer produtor que respeite as características tipificadas, circunscritas a uma determinada região. A segurança efetiva, tanto para consumidores, quanto para produtores e fornecedores, demanda um aparato técnico jurídico associado à certificação.

Com vistas a garantir a autenticidade e origem de seus produtos, os produtores passaram a utilizar selos distintivos naqueles. Notam-se aí aspectos da concorrência desleal, e a necessidade do estabelecimento de normas legislativas capazes de proteger eficazmente os direitos dos produtores que se delineavam na época. (CALLIARI et al, 2007, p.2).

A IG delimita a área de produção, restringindo seu uso aos produtores da região (em geral, reunidos em entidades representativas). Ao manter os padrões locais, ela impede que outras pessoas utilizem indevidamente o nome da localidade em produtos ou serviços. No Brasil, o registro de IG foi estabelecido pela Lei 9279/96 - LPI/96 e considera IG a IP e a DO, dando ao INPI a competência para estabelecer as condições de registro das IG (INPI, 2013).

A IP reporta-se ao nome do local ou região que se tornaram conhecidos, de onde se extrai ou onde se produz determinado produto (ou serviço). A DO refere-se ao nome do local, que passou a designar produtos ou serviços, cujas características são atribuídas à sua origem geográfica, devem-se exclusiva ou essencialmente ao meio geográfico, incluídos fatores naturais e humanos. Uma IP assegura que o produto ou serviço tem características próprias de produção que o diferencia dos demais. A diferenciação pode se caracterizar pela tradição da técnica de produção, por sua reputação no mercado local e nacional.

As características do clima, espaço ou técnica, asseguram qualidade diferenciada do produto protegido pela IP. Por ser mais específica, a DO é mais difícil de ser obtida. Neste caso, tem que haver a associação de características próprias de produção com o caráter geográfico da região, ou seja, a DO é a garantia de que o produto com aquela denominação não pode ser encontrado em nenhum outro local. As características geográficas do local (solo, clima, relevo), associadas às técnicas tradicionalmente estabelecidas no local geográfico 
determinam que nenhum outro produto de outra região poderá ter o nome associado ao produto protegido.

A IP é uma garantia legal de que um produto é originário de determinada região. Após a obtenção da IP, a identificação do produto pode ser feita por grupos organizados, a exemplo de uma associação, que demonstra ao produtor interessado as etapas de produção a serem seguidas conforme o Regulamento Técnico de Produção. A associação deve também auxiliar e valorizar a participação de todos os membros da produção.

Dentre os dois conceitos utilizados no Brasil, o azeite de dendê da região de Valença pode ser melhor representado por uma IP. O que se verifica no dendê de Valença é o reconhecimento da sua qualidade, inclusive nos municípios vizinhos, e no principal mercado, a cidade de Salvador. A sua reputação e qualidade o diferencia dos demais produzidos em outras regiões.

\subsection{CONDIÇÕES GERAIS PARA A CERTIFICAÇÃO}

Com base nas informações levantadas, nas experiências exitosas e nos aspectos conceituais e técnicos, podem-se sinalizar, sinteticamente, quatro condições para a efetivação de uma IP:

1) existência de um mercado de consumo que demande produtos com especificidades;

2) características específicas de produção e de solo, matéria-prima, técnicas de manejo e beneficiamento, que ocasionem o reconhecimento, ao menos local, da qualidade do produto;

3) existência de organização local capaz de organizar e mobilizar os produtores locais para a pesquisa, busca de apoio e acesso a mercados, e assegure a obediência a padrões de produção;

4) A existência de suporte estatal ou privado à produção e à iniciativa pela certificação.

\section{O AZEITE DE DENDÊ}

Para uma possível IG do azeite de dendê consideram-se alguns elementos associados: significado do produto, suas especificidades e qualidades particulares em uma região (Valença), além dos elementos culturais associados ao cultivo, beneficiamento e consumo. 
O dendê é uma espécie vegetal originária da costa africana e foi inicialmente encontrado em povoamentos subespontâneos. O seu óleo passou a ser produzido no Brasil, a partir do século XVI, pelos escravos que trouxeram as primeiras sementes. O azeite de dendê é um óleo valorizado e amplamente comercializado no mercado mundial, principalmente pelo seu baixo nível de acidez, maior rendimento por área e processo de extração como o da prensa, ao contrário dos demais óleos vegetais, a exemplo do óleo de soja que, em sua maior parte, depende do uso de solventes químicos. (SEAGRI, 2002).

O fruto é classificado conforme a espessura do endocarpo. Destacam-se as variedades Dura (endocarpo com espessura entre 2 a $6 \mathrm{~mm}$ ); Psífera (frutos sem endocarpo separando polpa da amêndoa); Tenera (híbrido do cruzamento Psifera e Dura, endocarpo entre $0,5 \mathrm{~mm}$ e $2,5 \mathrm{~mm}$ ). A híbrida, que tem vida econômica mais curta (20 a 30 anos), é tecnicamente recomendada para plantios comerciais, mas há controvérsia. A variedade Dura, embora mais resistente a doenças, não apresenta o mesmo rendimento físico que a Tenera. (CEPLAC, 2000).

A produção começa no final do terceiro ano após o plantio, com 6 a 8 toneladas por hectare. O máximo ocorre no oitavo ano, quando pode atingir 25 toneladas. Dos frutos do dendezeiro, podem ser extraídos dois tipos de óleo: óleo de polpa, internacionalmente conhecido como óleo de palma (azeite de dendê), e o óleo de palmiste (extraído do coquilho). Estimam-se $22 \%$ do peso dos cachos para o óleo de polpa, e $2 \%$ para o óleo de palmiste. (CEPLAC, 2000).

A Bahia possui grande diversidade de solos e clima para a cultura do dendezeiro. Destacam-se fatores climáticos como regime pluviométrico ideal de precipitação média anual entre 1.800 e $2.000 \mathrm{~mm}$, altos níveis de radiação solar e pequenas variações de temperatura. A maior parte do óleo baiano provém de dendezeiros subespontâneos que ocupam pouco mais de 19 mil ha.

\subsection{PRODUTOS DO DENDEZEIRO}

O dendê é matéria-prima para uma série de produtos, não se restringindo ao azeite, popular na culinária baiana. É no ramo alimentício que se encontra a qualidade merecedora de registro. Além das características distintivas dos seus produtos, a cultura do dendê possui como diferencial o baixo impacto ambiental e a possibilidade de cultivo em solos pobres, conforme sinaliza relatório da Companhia Nacional de Abastecimento - CONAB: 
É considerada uma cultura com forte apelo ecológico, por apresentar baixos níveis de agressão ambiental, adaptar-se a solos pobres, protegendo-o contra a lixiviação e erosão e "imitar" a floresta tropical. A dendeicultura tem ainda, a capacidade de ajudar na restauração do balanço hídrico e climatológico, contribuindo de forma expressiva na reciclagem e "seqüestro de carbono" e na liberação de $\mathrm{O} 2$, contribuindo assim no combate da elevação excessiva das temperaturas médias do Planeta. (CONAB, 2006, p.4).

Diante desses fatores, há a previsão de progressão da demanda podendo o óleo de dendê se tornar o principal produto do seu gênero, conforme sinaliza Semedo:

O dendezeiro é a oleaginosa que apresenta a maior produtividade de óleo por área cultivada, chegando a 8 toneladas por hectare, equivalente a 10 vezes mais do que a soja [...]. O preço do óleo de dendê tem se mantido estáveis em torno de US $\$ 450,00$ a tonelada. Esse nicho de mercado movimento anualmente US $\$ 30$ bilhões e as previsões indicam que o consumo desse óleo deve superar o da soja nos próximos três anos. (SEMEDO, 2006, p.36).

Em resumo, observam-se dois grandes usos distintos: matéria-prima para produtos medicinais, industriais, oleoquímicos e gêneros alimentícios. Entre os primeiros, destacamse sabões, detergentes, amaciantes, combustíveis e uso na siderurgia. Entre os alimentos, Souza (2000) aponta a fabricação de pães, bolos, tortas, biscoitos finos e cremes e, no caso específico do azeite de dendê, há o diferencial de conservar importantes características nutritivas, como a presença de vitaminas e antioxidantes. Tudo isso importa, para além da cozinha regional.

\subsection{ACOMMODITY AZEITE DE DENDÊ}

O azeite ou óleo de dendê é uma importante commodity (mercadoria), conhecida no mercado internacional como palmoil (óleo de palma). Além da sua dimensão econômica, a expectativa é de um mercado potencial promissor.

Curvelo (2010) aponta as propriedades nutricionais do óleo de dendê: trata-se de um alimento riquíssimo em vitamina $\mathrm{A}, \mathrm{E}$ e B; atua como antioxidante, rico em betacaroteno e niacina; apresenta alta concentração de ácidos graxos e estabilidade térmica. Possui variabilidade nas suas características físicas, de acordo com especificidades na produção e beneficiamento.

O azeite de dendê é percebido como o mais promissor dos óleos vegetais no mercado mundial. O baixo impacto ambiental, a adaptabilidade do plantio a solos pobres, a alta produtividade e a qualidade do produto final são apontados como vantagens competitivas: 
Substitui a gordura animal na culinária com vantagens para a saúde humana; sua produtividade é maior do que a de produtos concorrentes $(3.500 \mathrm{a} 6.000 \mathrm{~kg} / \mathrm{ha}$ de óleo de palma, contra $400 \mathrm{a}$ $600 \mathrm{~kg} / \mathrm{ha}$ do óleo de soja, $800 \mathrm{a} 1.100 \mathrm{~kg} / \mathrm{h}$ a do óleo de colza e 600 a $1.000 \mathrm{~kg} / \mathrm{há}$ do óleo de girassol); a dendeicultura exige pouca mecanização e reduzido emprego de defensivos agrícolas. (CURVELO, 2010, p.18).

Conclui-se que o óleo de dendê possui características determinantes para seu aproveitamento econômico. Primeiramente, pela sua expansão no mercado internacional, tendendo a liderar óleos vegetais. Segundo, porque proporciona maior lucratividade. Terceiro, porque associa maior produtividade com baixo impacto ambiental.

\subsection{ASPECTOS SOCIAIS E ECONÔMICOS DA PRODUÇÃO DO AZEITE DE DENDÊ}

Primitivamente, o dendê era produzido em pilões manuais, apenas para autoconsumo doméstico. Algum excedente começou a ser produzido nos rodões. Rodão é o tradicional nome que se dá ao local onde ocorre o processo de produção do azeite. Após o corte, os cachos são transportados por animais. O produto é cozido em um tacho, por um dia, e depois é levado para uma prensa artesanal, onde é feita a extração do azeite.

O crescimento dos mercados exige abastecimento regular. Alguns rodões passaram a ser parcialmente mecanizados ou semi-industrializados. Os frutos são cozidos em caldeirões, em seguida macerados e levados à prensa, que separa o óleo dos resíduos. A substituição do rodão pelo macerador a diesel começou nos anos 1960. Essa inovação combina aumento de produtividade com redução de mão-de-obra. As inovações (radical e incremental) estão associadas às idades tecnológicas, conforme sinaliza Couto Filho et al (2004):

É de se esperar que uma inovação radical surja [...] como uma inovação significativa na base do conhecimento científico e tecnológico, provocando ruptura no velho paradigma. Já pequenas inovações que fazem num mesmo paradigma, ao longo de uma trajetória, são inovaçôes incrementais. Elas são importantes para a rentabilidade da empresa, mas não tem o significado de uma inovação radical. (COUTO FILHO et al apud DIAS, 2007, p.35).

Na história da produção observam-se diferentes idades tecnológicas. Com a chegada da energia elétrica, em 1975, substituíram-se motores a diesel, sem mudança significativa na estrutura produtiva, caracterizando-se uma inovação incremental. A simples troca de 
motores não modificou a base tecnológica da produção. O seu uso (diesel e elétrico) fez aumentar em $86 \%$ a produção comparativamente à tração animal. Mais uma vez, aumenta o volume de produção com diminuição da mão-de-obra, particularmente feminina, responsável pela lavagem do óleo, que passou a ser feita pela máquina. (DIAS 2007). O quadro 1 apresenta as inovações tecnológicas no beneficiamento do dendê e seus respectivos resultados, em Cajaíba, município de Valença - Bahia.

Quadro 1 - TECNOLOGIAS UTILIZADAS NO BENEFICIAMENTO DO DENDÊ

\begin{tabular}{lccccc}
\hline Tecnologia & Tipo & $\begin{array}{c}\boldsymbol{V} . \\
\text { Prod./Semana }\end{array}$ & $\begin{array}{c}\text { Produtividade/ } \\
\text { Ton }\end{array}$ & $\begin{array}{c}\boldsymbol{U} \text { TF } \\
\text { média }\end{array}$ & Litros/dia \\
\hline Pilão & - & 1 tonelada & 6 a 7 latas & 1 & 2,5 \\
\hline Rodão & Radical & 7 toneladas & 6 a 7 latas & 4 & 18 \\
\hline Mac. Diesel & Radical & 42 toneladas & 6 a 7 latas & 5 & 108 \\
\hline Mac. Elet & Increm. & 49 toneladas & 6 a 7 latas & 3 & 126 \\
\hline Prensa & Increm. & 98 toneladas & 9 latas & 5 & 504 \\
\hline
\end{tabular}

Fonte: DIAS, 2007

Observe-se o significativo aumento na eficiência técnica. Do pilão à prensa, último estágio tecnológico da produção do azeite comestível, a produção diária passou de 2,5 a 504 litros.

\section{VIABILIDADE DE UMA IP PARA O AZEITE DE DENDÊ DE VALENÇA}

Importa agora verificar a possibilidade de se atribuir uma IP ao azeite de dendê produzido na região de Valença. Após análise dos elementos conceituais e técnicos, realizada nas seções anteriores, observou-se o produto em relação a: existência de nicho ou segmento de mercado; características da produção e reconhecimento local da qualidade do produto; existência de uma organização local; existência de apoio governamental e privado.

\subsection{CARACTERÍSTICAS DO MERCADO}

O mercado mundial de palmoile é liderado pela Indonésia e Malásia, juntos, produzem 46,5 milhões de toneladas e dominam a quase totalidade das exportações mundiais. $\mathrm{Na}$ produção, a participação do Brasil ainda é muito pequena (275 mil de toneladas), ocupando a nona colocação no ranking de países produtores, segundo relatório anual Oil World, de 2010. No Pará, maior estado produtor, encontram-se mais de $80 \%$ da área plantada com dendezeiros.

Apesar do vínculo com a sua culinária, a Bahia é apenas o quarto produtor brasileiro, depois do Pará, Amazonas e Amapá. A produção baiana concentra-se na região do Baixo 
Sul, em torno do município de Valença. Os dendezeiros são, em sua maioria, subespontâneos, do tipo comum ou dura. Todavia, um trabalho de incentivo ao cultivo da qualidade tenera vem sendo realizado por cooperativas como a Cooperativa de Fomento Agrícola de Valença (Coofava). O estado possui características favoráveis, conforme sinaliza relatório governamental:

A Bahia possui uma diversidade edafoclimática excepcional para o cultivo do dendezeiro, com uma disponibilidade de área da ordem de 854 mil ha, em áreas litorâneas que se estendem desde o Recôncavo Baiano até os tabuleiros do Sul da Bahia, porém apenas 41.486 hectares estão sendo cultivados. (CONAB, 2006, p.5).

Percebe-se, assim, um potencial ainda não explorado na região estudada, uma vez que o palmoil vem ganhando espaço no mercado mundial.

\subsection{BAHIA: CULTURA E ESPECIFICIDADES REGIONAIS}

O azeite de dendê, na Bahia, é matéria-prima para uma série de alimentos da culinária regional. Esses gêneros alimentícios compõem um ambiente identitário da população sendo, inclusive, objeto de esforços de preservação e valorização.

Frente a essas considerações, o acarajé foi oficializado como Patrimônio Cultural Imaterial Brasileiro através do Ofício da Baiana, em dezembro de 2004. Esse bolinho, dentre os outros pratos de herança africana, é tradicional na venda de comida de rua de Salvador e tem significado importante tanto no espaço social quanto no religioso. (SILVA et al., 2011, p.2).

A Bahia possui um dos maiores contingentes populacionais negros do Brasil e a identidade racial é um importante componente da cultura local. A capoeira, as religiões e os alimentos de origem africana compõem o referencial simbólico do estado. O candomblé, religião de matriz africana, está relacionado a rituais que envolvem animais e alimentos, dentre os quais muitos utilizam o dendê como ingrediente.

Uma das maiores evidências documentadas da presença do dendê na cultura da Bahia é a obra do escritor Jorge Amado. Segundo Abbade (2013), o abará, o acarajé e a farofa de dendê têm presença garantida nas principais obras do romancista. Os alimentos à base de 
dendê descritos por Jorge Amado pertencem, na maior parte dos casos, à esfera do sagrado nos rituais do candomblé, onde as iguarias se constituem como oferendas às divindades. Para essa religião, a cozinha é um local importante. Ali começa a formação de muitas mães-desanto, principal autoridade religiosa dos terreiros de candomblé.

$\mathrm{Na}$ culinária afro-baiana, o dendê aparece na quase totalidade dos pratos. Sua presença extrapola a dimensão religiosa, sendo amplamente consumido pela população local. Segundo Barroco (2013), a culinária à base de dendê atua como uma espécie de "relações públicas" da região, estimulando o turismo no estado e fortalecendo o mercado consumidor local.

Cultura e produção não estão dissociadas, ambas têm forte relação. A cultura do dendê foi trazida à Bahia pelos escravos africanos, no século XVI. Conforme observado na seção 3.3, a produção permaneceu, por séculos, como resultado de um esforço de base familiar, com emprego de técnicas artesanais, a exemplo do pilão. Apenas no século XX ocorreram inovações significativas na base tecnológica, particularmente do beneficiamento do dendê: do pilão aos rodões (diesel e elétrico), em seguida a prensa, sempre com aumento de produtividade. Até os dias de hoje verifica-se a presença simultânea de todas as técnicas já utilizadas, sendo que entre os agricultores familiares o mais comum é o emprego do rodão a diesel e elétrico. Instalar uma prensa individual e privada requer um montante de recursos que extrapolam as expectativas de ganhos nas unidades familiares. Esse salto tecnológico só se viabiliza coletivamente, por grupos de produtores, em associações ou cooperativas.

\subsection{COOFAVA}

As cooperativas são fruto de lutas sociais dos trabalhadores pela própria sobrevivência. Impossibilitados de competir sozinhos no mercado, pequenos produtores ficam restritos a grupos para elevar a sua competitividade. Entre as diversas formas de organização, destaca-se a cooperativa. Em Valença, o que se busca é a redução dos problemas próprios dos pequenos agricultores locais, como: baixo uso de tecnologias apropriadas (análise, correção e manejo de solos, adubos, genética apropriada, controle de pragas, adensamento, controle da sombra, etc.); baixos preços; falta de capacitação e ausência de programas apropriados.

A Coofava existe desde 1996, mas só ganhou força em 2008 ao contratar o fornecimento de guaraná natural para a Companhia de Bebidas das Américas (AMBEV). O preço do guaraná mais do que dobrou. Valorizou-se também o cravo-da-índia, e, a partir de 
2012, elevaram-se os preços do dendê e seus derivados. Uma das ações da cooperativa consiste em estimular o plantio da variedade Tenera, que produz até 30 toneladas por ha. Cada tonelada rende $220 \mathrm{~kg}$ de azeite e $30 \mathrm{~kg}$ de óleo de palmiste. (COOFAVA, 2012).

\subsection{AÇÕES GOVERNAMENTAIS E PRIVADAS}

As iniciativas de preservação do patrimônio cultural foram acompanhadas de ações governamentais de incentivo e modernização da produção, através do governo do estado.

Com a finalidade de orientar tecnicamente os rodões, o Governo do Estado da Bahia, através da Secretaria de Agricultura (Seagri) e da Secretaria da Indústria, Comércio e Mineração (SICM), criou o Programa de Desenvolvimento da Dendeicultura Baiana e o Programa de Desenvolvimento da Cadeia Agro-industrial do Dendê, que tem como participantes a Ceplac, EBDA, Banco do Nordeste, Banco do Brasil, as empresas Opalma, Oldesa, Jaguaripe e Mutupiranga, assim como cooperativas de produtores rurais, associações dos municípios da região do Baixo Sul, associação dos proprietários de "roldões" e o Instituto de Desenvolvimento Regional Sustentável do Baixo Sul - IDES. (CONAB, 2006, p.7).

Pode-se admitir a existência de uma importante rede ativa de suporte à cultura do dendê na Bahia, envolvendo o governo do estado da Bahia, órgãos federais, empresas de economia mista, empresas privadas e associações locais.

A própria Coofava é protagonista na articulação de uma rede complementar de parceiros que dão suporte à produção, para fomentar a agricultura profissionalizada na região. Construiu relações de confiança com instituições como: Banco do Brasil (Desenvolvimento Regional Sustentável - DRS); CONAB, através do Programa de Aquisição de Alimentos (PAA). Estoque para o Cravo da Índia e para o Guaraná; Prefeitura Municipal de Valença; Criação, apoio e gestão do Conselho de Desenvolvimento Rural Sustentável (CMDRS); Articulação com a Comissão Executiva de Planejamento da Lavoura Cacaueira (Ceplac), Empresa Baiana de Desenvolvimento Agrícola (EBDA) para emissões da Declaração de Aptidão do Produtor (DAP) que consiste como instrumento de identificação do agricultor familiar para ter acesso a programas do governo; elaboração de projetos para o Programa de Fortalecimento da Agricultura Familiar (Pronaf); Associação dos Municípios 
da Região do Baixo Sul da Bahia (AMUBS) em Articulações Institucionais diversas; parceria com a Cooperativa de Crédito (Ascoob) para estruturação do escritório e articulação para o crédito.

Dentre essas parcerias destacam-se a DRS, através do Banco do Brasil, e o PAA, através da CONAB. Esses programas, acima de tudo, buscam dar condições e estímulos à manutenção do pequeno produtor na atividade agrícola. Os órgãos governamentais e privados tentam evitar o êxodo desses agricultores familiares que muitas vezes não conseguem obter, de forma isolada, renda suficiente para uma subsistência baseada exclusivamente na agricultura familiar.

Ao divulgar o DRS, o Banco do Brasil informa que aquele programa de desenvolvimento sustentável consiste na mobilização de agentes econômicos, sociais e políticos para o apoio a atividades produtivas economicamente viáveis, observada e respeitada a diversidade cultural. Tem como parte de seus objetivos a promoção da inclusão social, por meio da geração de trabalho e renda, a democratização do acesso ao crédito, o reforço do associativismo e do cooperativismo, a contribuição para a melhora dos indicadores de qualidade de vida e solidificação dos negócios com micro e pequenos empreendedores rurais e urbanos, formais ou informais.

No PAA, executado pela CONAB, empresa oficial do Governo Federal, encarregada de gerir as políticas agrícolas e de abastecimento, propõe-se a geração de renda e sustentação de preços aos agricultores familiares, o fortalecimento do associativismo e do cooperativismo. O programa valoriza a produção e a cultura alimentar das populações, dinamizando a economia local, a formação de estoques estratégicos, a melhoria da qualidade dos produtos da agricultura familiar, o incentivo ao manejo agroecológico dos sistemas produtivos e ao resgate e preservação da biodiversidade (CONAB, 2013).

Através dos programas como: Compra Direta da Agricultura Familiar (CDAF), Compra da Agricultura Familiar com Doação Simultânea (CPR - Doação), e Formação de Estoque pela Agricultura Familiar (CPR - Estoque), a CONAB adquire produtos dos pequenos agricultores. O PAA é voltado para agricultores familiares enquadrados no Pronaf, inclusive povos e comunidades tradicionais como quilombolas, famílias atingidas por barragens, trabalhadores rurais sem terra acampados, comunidades indígenas e pescadores artesanais. (CONAB, 2013) 
As associações contribuem nessas parcerias dando informação e força aos pequenos produtores que muitas vezes não têm acesso ao crédito e aos programas de incentivo, quando isolados desses grupos organizados. Além disso, a cooperativa também contribui fornecendo suporte técnico com relação aos métodos de produção.

\section{CONSIDERAÇÕES FINAIS}

A IG e suas categorias específicas IP e DO vêm sendo utilizadas para diferenciar produtos, atestando suas características peculiares do ponto de vista da produção, do suporte tecnológico e da relação com elementos históricos regionais. Em um mercado de consumo de massa, com tendência à homogeneização de produtos, esse tipo de certificação protege produtores e consumidores, além de se constituir em importante diferencial que pode conferir acesso a mercados específicos e clientes exigentes.

Os casos de maior destaque no mundo são os vinhos europeus, a exemplo das regiões de Bourdeaux, Porto e Champagne. No Brasil, existem experiências exitosas, dentre as quais se destaca a do Vale dos Vinhedos, na Serra Gaúcha. O seu reconhecimento contribuiu para a profissionalização da produção e conferiu maior lucratividade aos produtores, valorizando o seu patrimônio, tanto familiar quanto empresarial. Trata-se de uma estratégia importante para enfrentar barreiras não-tarifárias e dar acesso a novos mercados. No Brasil, essa estratégia ainda vem sendo empregada de forma muito tímida, em comparação, por exemplo, com outros países em desenvolvimento, como a China.

Para que um registro de IP seja assegurado e traga benefícios aos produtores, é necessário o cumprimento dos seguintes pré-requisitos regulamentares: 1) existência de um mercado de consumo relacionado ao produto; 2) elementos específicos de produção e reconhecimento local da qualidade; 3) organização local dos produtores em torno de uma cooperativa ou associação; e 4) uma rede de suporte estatal e privada, que dê apoio à iniciativa.

Será possível afirmar que há viabilidade na outorga de uma IP para o azeite de dendê da região de Valença - Bahia? Partindo da pergunta, tentou-se compreender as características desse produto e de sua produção. O azeite de dendê, ou palmoil, como é conhecido no mercado internacional, tem potencial para vir a se consolidar como o óleo vegetal mais consumido no mundo. Possui características alimentícias benéficas, sendo rico em nutrientes. Além disso, trata-se de uma cultura própria de regiões tropicais e com baixo impacto ambiental, comparada a outras culturas. Apesar de se constituir como matéria-prima para 
uma série de itens, como insumos industriais e até substituto energético, estudos apontam que, em Valença, é no aproveitamento alimentício que o dendê encontra o seu mercado mais amplo e maior lucratividade para os produtores.

O Brasil ocupa ainda uma posição tímida no cenário global de produção do dendê, voltado quase exclusivamente ao mercado doméstico. No ranking mundial, liderado por países asiáticos, o país ocupa apenas a nona colocação entre os produtores. No mercado nacional, o Pará é responsável por mais da metade da produção. A Bahia, apesar de ter clima e solo favoráveis, ocupa uma parcela muito reduzida desse mercado, existindo, portanto, espaço para expansão. $O$ dendê também está associado a importantes elementos culturais baianos, particularmente na culinária. O acarajé, por exemplo, um dos alimentos que utiliza o azeite como ingrediente, já está registrado como patrimônio imaterial, com proteção estatal. No mercado baiano, o azeite de dendê produzido em Valença é reconhecido pela população como o de melhor qualidade.

São necessários, portanto, dois requisitos para se fazer um pedido de registro de IG: existe um mercado global em expansão de consumo de palmoil e o azeite de dendê de Valença possui características peculiares cuja qualidade é reconhecida localmente. Faz-se necessário, no entanto, a realização de estudos técnicos para detalhar essas especificidades do produto da região. Além disso, verifica-se que ainda ocorre em muitas propriedades, conforme relatos de estudos e balanços governamentais, o emprego de técnicas de baixa produtividade na cultura do dendê. Constatou-se a necessidade de uma ampliação na difusão do emprego da prensa, inclusive de uso coletivo, em substituição aos rodões, em função da sua maior efetividade e baixo impacto ambiental.

A Cooperativa de Fomento Agrícola de Valença tem o potencial de cumprir o outro elemento indispensável para o sucesso de uma IG no conceito de IP: a existência de uma organização local de produtores, capaz de articular os esforços em torno para requerimento de um registro junto ao INPI. A Coofava possui experiência exitosa no estímulo à produção de outras matérias-primas, como o guaraná e o cravo-da-índia, mas suas iniciativas em relação ao azeite de dendê ainda são incipientes, tendo-se iniciado em 2012. Faz-se necessário, portanto, uma ampliação da experiência, já em andamento, com o estímulo da utilização da prensa e a realização de novas pesquisas associadas ao palmoil.

De forma complementar à atuação da Coofava, verifica-se a existência do quarto requisito para um pedido de registro, que é a constituição de uma rede de apoio à iniciativa, com parceiros públicos e privados. A dendeicultura é objeto de políticas públicas específicas, 
com apoio do governo do estado da Bahia e de órgãos do governo federal, a exemplo da Ceplac. A cooperativa também possui suporte de bancos de economia mista para a obtenção de crédito para a produção.

Com base nas análises realizadas, pode-se concluir que a produção do azeite de dendê na região de Valença reúne, potencialmente, os requisitos para se requerer uma IP. No entanto, há a necessidade de estudos complementares, detalhando a demanda por esse tipo de produto diferenciado e as características específicas do azeite de dendê de Valença.

\section{REFERÊNCIAS}

ABBADE, Celina Maria. A comida baiana de Jorge Amado revelando o léxico africano. Xique-Xique, 2012. Disponível em: <http://www.uneb.br/xiquexique/dcht/files/2012/08/A comida baiana-Celina Abbade.pdf> Acesso em 30 mar. 2013.

ADPIC. Acordo Sobre Aspectos dos Direitos de Propriedade Intelectual Relacionados ao Comércio. Disponível em: <http://www.cultura.gov.br/site/wpcontent/uploads/2008/02/ac trips.pdf > Acesso em 15 jan. 2013.

BARROCO, Lize Maria Soares. A importancia da gastronomia como patrimônio cultural no turismo baiano. Curitiba, 2013. Disponível em: < http://www.obsturpr.ufpr.br/artigos/alimbeb1.pdf>. Acesso em 20 mar. 2013.

CALLIARI, M.A.C. et al. Proteção às indicações geográficas: a experiência brasileira. In: XII SEMINÁRIO LATINO-IBEROAMERICANO DE GESTION TECNOLÓGICAALTEC 2007, Buenos Aires, Argentina. Disponível em: $<$ http://www.ige.unicamp.br/geopi/publicacoes.php?sub=artigos $>$ Acesso em 20 mar. 2013.

COMPANHIA NACIONAL DE ABASTECIMENTO - CONAB. Dendeicultura na Bahia. Salvador, 2006. Disponível em: $<$ http://www.conab.gov.br/conabweb/download/sureg/BA/dendeicultura na bahia.pdf >. Acesso em 02 fev. 2013.

CURVELO, Fabiana Martins. Uma imersão no tabuleiro da baiana: o estudo do óleo de palma bruto (elaeisguineensis). 2012. 103f. Dissertação (Programa de Pós-Graduação em Alimentos, Nutrição e Saúde Mestrado em Alimentos, Nutrição e Saúde) - Universidade Federal da Bahia - UFBA, Salvador, 2010.

DIAS, Washington L. S. N. Do Pilão à prensa: um caso de inovação tecnológica no beneficiamento do dendê em Valença, Bahia. 2007. 57fl. Trabalho de conclusão de curso (Graduação) - Faculdade de Ciências Econômicas - UFBA, Salvador, 2007

INPI (Instituto Nacional de Propriedade Intelectual). Disponível em: <www.inpi.gov.br>. Acesso em 17 jan. 2013. 
LEMOS et al. A organização territorial da indústria no Brasil. In: DE NEGRI, J. A.; SALERNO, M. S. (orgs.). Inovações, padrões tecnológicos e desempenho das firmas industriais brasileiras. Brasília: IPEA, 2005.

MAIA, J. de M. Economia internacional e comércio exterior. São Paulo: Atlas, 2004, $9^{a}$ ed.

REIS, Lívia Liberato de Matos. Indicação de Procedência: uma nova dimensão da competitividade para o território da Apaeb - Valente. 2008. 206 fl. Dissertação (Mestrado em Desenvolvimento Regional e Urbano). Universidade Salvador UNIFACS, Salvador, 2008.

SEAGRI - Bahia. Secretaria de Agricultura... Cultura Dendê. Disponível em: < http://www.seagri.ba.gov.br/Dende.htm\#BIBLIOGRAFIA > Acesso em 20 mar. 2013.

SEMEDO, Isidoro. O mercado de energia renovável: viabilidade econômica do dendê na agricultura familiar do baixo sul-Babia.2006. 119f. Dissertação (Mestrado em Economia). Universidade Federal da Bahia. Salvador, 2006.

SILVA, Iane Carina de Freitas da et al. As interfaces dos discursos de preservação do patrimônio cultural $e$ da promoção da alimentação saudável em torno da produção e consumo do acarajé.XI Congresso Luso Afro Brasileiro de Ciências Sociais. Universidade Federal da Bahia, Salvador, 2011.

VALENTE, Maria Emília Rodrigues et al. Indicação geográfica de alimentos e bebidas no Brasil e na União Europeia.in Revista Ciência Rural, v. 42, n 3. Santa Maria: UFSM, março de 2012. 